176 Bestimmung d. Phosphorsäure etc. - Silber im Bismuthum etc.

\title{
Die Bestimmung der Phosphorsaure im Bier als Mittel zur Beurtheilung des Malzgehaltes.
}

Unter Mitwirkung des Malzzuckers geht nebst denl eicht löslichen phosphorsauren Alkalien nur ein Theil der Erdphosphate aus dem Malz in Lösung, die auch beim Verschwinden des Zuckers durch fortschreitende Gährung in Lösung bleiben, indem die gleichzeitig mit Alkohol gebildete Milchsäure, Essigsäure und Glycerin das Ausscheiden derselben verhindern.

Nach Prof. Aug. Vogel enthält ein Liter Winterbier 0,5, Lagerbier 0,6 und Bockbier 0,9 g. gebundene $\mathrm{PO}^{5}$.

Zur Bestimmung der Phosphorsäure benutzt man nach Th. Diez am besten Uranoxydlösung nach Neubauer und Vogel. Durch die Phosphorsäurebestimmung lassen sich alle fremdartigen Malzzusätze erkennen, indem das Bier einen geringeren Gehalt an $\mathrm{PO}^{5}$ besitzt. (Neues Jahrb. f. Pharmacie. $B d$. XXXIX. Heft 1.).

C. Schulze.

\section{Silber im Bismuthum nitricum des Handels.}

Ch. Erin bekam eine Sendung Bismuthum nitricum, was so viel Silber enthielt, dass es sich am Lichte blauschwarz färbte. Er unterwarf 15 verschiedene Sorten der Analyse und fand in $\mathbf{7}$ derselben Silber. Mehrere Sorten waren kein Wismutnitrat, sondern ein basisches Wismuthsubchlorid, von welchen 1 Sorte $90 \%$ enthielt; in anderen betrug es $6,5-4,9-3,9-1 \%$, während es in noch anderen spurweise bald mit, bald ohne Silbergehalt auftrat. Das Subchlorid ist wohlfeiler und wird jedenfalls absichtlich zugemischt. Beide Verunreinigungen können dadurch entstehen, dass nach dem Auflösen des $\mathrm{Bi}$ das Silber aus der Lösung mit Salzsäure ausgefällt und der Niederschlag durch Abgiessen von der Flïssigkeit getrennt wird. Geschieht dieses nicht sorgfältig, so ergeben sich obige Beimengungen. (Pharm. Journ. and Transact. Nov. 16. p. 381. 1872. Neues Jahrb. für Pharmac. Bd. XXXIX. Heft L).

C. Schulze.

Wird in Deutschland selten vorkommen. Rdt. 